\title{
NAS TRAMAS DO NHANDUTI: TECENDO A IGUALDADE DE GENERO NUM INSTITUTO FEDERAL DE FRONTEIRA
}

\section{IN THE NHANDUTI WEFT: WEAVING GENDER EQUALITY AT A VO-TECH HIGH SCHOOL IN THE BORDER}

\author{
Eli Gomes Castanho* \\ Fabrícia Carla Viviani** $^{* *}$
}

\begin{abstract}
Resumo: Este artigo trata da análise de textos produzidos no contexto do ensino médio integrado, em razão da participação em um concurso nacional voltado para a temática da igualdade de gênero. Tais textos configuraram-se como produto final de uma oficina elaborada especialmente para repertoriar os estudantes nesse processo. Nosso objetivo, aqui, é perceber por meio da análise documental, de cunho qualitativo, como os textos dessas/es alunas/os-autoras/es deixam entrever a apropriação de um discurso em favor à igualdade de gênero e de combate à violência contra a mulher. Para isso, apoiamo-nos nas leituras sobre multiletramentos, somadas às leituras do campo das teorias de gênero, com as quais buscamos dialogar num movimento analítico que tem como ponto de partida os textos produzidos pelas/os alunas/os. Os resultados apontam para a problematização sobre o silenciamento acerca da violência sofrida, bem como de sua naturalização, o que contribui para a culpabilização da vítima. Além disso, ficaram evidentes aspectos da interculturalidade local e a desconstrução de estereótipos generificados.
\end{abstract}

Palavras-chave: Ensino médio integrado; igualdade de gênero; produção de texto; violência contra a mulher.

Abstract: This article analyzes the texts produced in the context of a vocational-technical high school, on the occasion of students' participation in a national essay contest focused on the theme of gender equality. Such texts comprise the final product of a workshop specially designed for students to engage in this writing process. Here, the objective is to understand how their essays demonstrate an appropriation of a discourse that supports gender equality and the combat of violence against women. As a qualitative document analysis, the review of the texts was informed by the literature on multiliteracies and gender theory. The results obtained point to a problematization of the silencing over, and naturalization of, the violence suffered by women, which contributes to the blaming of the victim when such episodes occur. They also evidence aspects of students' local interculturality and the deconstruction of gender stereotypes.

Keywords: Vocational-technical high school; gender equality; text production; violence against a woman.

\footnotetext{
* Professor de Português e Espanhol no IFSP campus Salto. Doutor em Linguística Aplicada pelo IEL/UNICAMP, integrante do grupo "LIMC - Grupo Multidisciplinar de Pesquisa em Linguagens e Manifestações Culturais", vinculado ao IFSP/Salto. E-mail: eli.castanho@ifsp.edu.br

** Professora de Sociologia no IFMS campus Ponta Porã. Doutora em Ciência Política pela UFSCar, Pós-doutoranda pela Faculdade de Educação, da Universidade de São Paulo (FEUSP), integrante do Grupo de Pesquisa "Crianças, práticas urbanas, gênero e imagens", vinculado à FEUSP e do "Grupo de Pesquisa Interdisciplinar em Teoria Social, Literatura e Linguística", do IFMS. E-mail: fabricia.viviani@ifms.edu.br
} 


\section{Introdução}

Este trabalho tem como motriz a análise de textos de alunas/os do Instituto Federal de Mato Grosso do Sul (IFMS), campus Ponta Porã, na fronteira do Brasil com o Paraguai. As/os alunas/os-autoras/es, voluntariamente e em horário extracurricular, participaram de um projeto denominado "Oficina de Textos \& Ideias". Dentre as atividades do referido projeto, deu-se a participação no $10^{\circ}$ Concurso Construindo a Igualdade de Gênero, à época, promovido anualmente pela então Secretaria de Políticas para as Mulheres, que, dentre as premiações previstas em seu edital, constavam as categorias estudantes do ensino médio e escolas promotoras da igualdade de gênero. ${ }^{1}$ Participamos, então, nessas duas categorias. Especialmente sobre a primeira categoria, elaboramos uma sequência de atividades ${ }^{2}$ que precederam a escrita desses textos para $o$ concurso, planejadas por nós, na condição de professores de Língua Portuguesa e Sociologia, durante parte dos anos de 2014 e 2015.

Ao longo de 2014, o surgimento do concurso nos foi uma motivação para pensar atividades que estimulassem a leitura e escrita e favorecessem um posicionamento mais autoral ante à temática da igualdade de gênero. Foi assim que nasceu a sequência de atividades que chamamos de Igualdade de gênero na diversidade dos gêneros. A proposta consistia, basicamente em propor a fruição literária em cada encontro, bem como um registro semiótico dele, num diário coletivo, buscando oferecer repertório para a produção final do texto. Daí o jogo com o termo-chave, gênero, em que se lê, primeiramente como categoria analítica e, em seguida, como materialização da textualidade, em suas diversas possibilidades multimodais, portanto, no plural.

Nesse sentido, estávamos, também, em diálogo com a proposta dos (multi)letramentos novos (cf. ROJO, 2009; ROJO e BARBOSA, 2015; COPE e KALANTZIS, 2009) por incluir a diversidade de gêneros e suas semioses que ofereceriam repertório para a produção de um outro gênero, mais ligado à esfera literária do dizer. Além disso, constatamos, à época, a partir do Mapa da violência 2012 (cf. WAISELFISZ, 2012) que, Ponta Porã, o município na fronteira do Brasil com o Paraguai, listava em $12^{\circ}$ lugar entre os municípios brasileiros e o $1^{\circ}$ no Mato Grosso do Sul em homicídio feminino. A taxa de 6,1\% também coloca o estado no topo da lista, na quinta posição, sendo a capital Campo Grande, a $19^{\mathrm{a}}$ entre as capitais, com 5,4\% dos feminicídios. Esse aspecto indica que a violência contra a mulher cometida no Mato Grosso do Sul está localizada no interior, alavancada por Ponta Porã, uma vez que dentre os 100 primeiros municípios do Brasil, não há outro município do estado. Sendo assim, vimos que estávamos, também, em diálogo afinado com a pedagogia dos letramentos múltiplos, exatamente porque buscávamos a inserção de aspectos da cultura local em nosso agir.

Portanto, este artigo busca analisar como os textos das/os alunas/os participantes do projeto evidenciam marcas da apropriação de um discurso pró igualdade de gênero e de combate à violência contra a mulher. Ao fazê-lo, deixam entrever atravessamentos inerentes ao contexto de fronteira e de imigração, articulando-os à história pessoal,

\footnotetext{
${ }^{1}$ Concurso promovido pela Secretaria de Políticas para as Mulheres da Presidência da República (SPMPR), com apoio do Conselho Nacional de Desenvolvimento Científico e Tecnológico (CNPq), do Ministério da Educação e da ONU Mulheres.

${ }^{2}$ Sequência de atividades e não sequência didática, por não atender totalmente à proposta do Grupo de Genebra, conforme preconizado por Dolz et al. (2004).
} 
familiar, bem como sinalizam para o entrecruzamento de vulnerabilidades da mulher dessa localidade em suas trajetórias e condições particulares.

De um ponto de vista teórico, partimos dos desafios da inserção da questão de gênero na escola, revisitamos textos e contextos que circundam a temática da inclusão e da exclusão da questão de gênero no espaço escolar, bem como nos situamos como agentes de letramentos múltiplos, especialmente por centrar a cultura do entorno da escola em nossas práticas, buscando o entrelaçamento de aspectos culturais com os dados da violência contra a mulher (SOARES, 2019; MISKOLCI; CAMPANA, 2017; JUNQUEIRA, 2013; BIROLI, 2018; WAISELFISZ, 2015; MOITA LOPES, 2006; ROJO, 2009). Num segundo momento, durante a análise dos textos, buscamos entretecer diálogos com mais outras referências (KILOMBA, 2019; bell hooks, 2019; SANTOS e IZUMINO, 2005; SAFFIOTI, 1997; WAISELFISZ, 2012; MAHER, 2007, FEDERICI, 2017), a fim de tornar mais profícua nossa reflexão sobre experiência vivenciada com as/os estudantes.

Ainda que neste trabalho predominem aspectos da pesquisa documental, por privilegiar a análise dos textos escritos em razão do concurso, faz-se necessário relatar o processo pelo qual os dados foram gerados. Logo, trata-se de uma pesquisa documental com elementos que caracterizam o relato de experiência. Para a análise, foram mobilizadas seis categorias, que serão apresentadas mais adiante, de modo a perceber como se deu a apropriação da temática tratada no decorrer dos quinze encontros que antecederam a produção dos nove textos analisados.

Nosso fazer científico, e também pedagógico, pode ser comparado à arte do nhanduti, teia de aranha em guarani, que é também o nome dado a uma arte paraguaia feita por bordadeiras reerguidas da Guerra da Tríplice Aliança (como lá dizem) ou Guerra do Paraguai (como falam cá). Há quem diga "artesanato", mas preferimos chamar de arte, já que opressores, como denuncia Galeano (1993), assim classificariam o trabalho de los nadies (os ninguéns): "Que no hacen arte, sino artesanía" ${ }^{3}$. Por fim, a própria palavra "texto" tem relação etimológica com tecido e o ato de tecer. Desse modo, nosso objeto de estudo - o "tecido" feito pelas/os alunas/os, bordadeiras/os da palavra - nos instiga a descobrir a que fios eles se conectam e se atam.

Caberia, por fim, perguntar o motivo pelo qual se torna relevante o relato dessa prática, passados cerca de cinco anos dela. Acreditamos que lançar um olhar retrovisor, nesses tempos de obscurantismo e absurda "criminalização" daqueles que militam pelos direitos humanos, nos convoca à urgência de se garantir as discussões de gênero na agenda da escola, pois, acreditamos que as práticas de leitura e escrita, quando elaboradas para esse fim, podem substancialmente favorecer o posicionamento crítico sobre as identidades de gênero e, por conseguinte, contribuir para o enfrentamento de todo e qualquer tipo de violência, inclusive e particularmente aqui, a de gênero. Essa questão ganha contornos ainda mais urgentes, e atuais, se considerarmos que, na conjuntura atual da pandemia COVID-19, assim como o número de infectados e mortos, temos vivenciado o aumento exponencial da violência contra mulher em contexto de isolamento. ${ }^{4}$ Crise que revela de maneira mais radical as condições estruturais e históricas das diversas formas de opressão e exploração das mulheres.

\footnotetext{
3 Tradução nossa: "Que não fazem arte, mas sim, artesanato".

${ }^{4}$ O Estado de São Paulo, por exemplo, teve crescimento de 45\% nas ocorrências registradas em março de 2020, em comparação com o mesmo mês de 2019. Para maiores detalhes, ver. Relatório Violência
} 


\section{Considerações teóricas sobre gênero na escola e práticas de multiletramentos}

Presenciamos, nas últimas duas décadas, políticas públicas importantes que impulsionaram o debate das questões de gênero e sexualidade na escola, abrindo possibilidades de resistência e fomentando práticas educativas transformadoras. Entretanto, também é visível uma contraofensiva de grupos conservadores, sobretudo nos últimos cinco anos, com a finalidade de silenciar a temática no espaço escolar (cf. SOARES, 2019). Toda essa discussão vem ecoando em preocupações no âmbito legislativo, tanto no Congresso Nacional quanto em Câmaras Estaduais e Municipais e em seus respectivos conselhos de educação. ${ }^{5}$ Esses grupos buscam total silenciamento no que se refere ao debate das questões de gênero e sexualidade nas escolas, com a justificativa de que ele confronta valores morais e/ou religiosos e a família nuclear tradicional. No cotidiano escolar, isso se traduz num regime de controle e vigilância constante, deflagrado em várias frentes: educadores, práticas pedagógicas e materiais educativos.

Historicamente generificada, a escola organiza institucionalmente a reprodução do modelo específico de masculinidades e feminilidades, mas o silenciamento dos últimos anos atribuiu à pauta de gênero um caráter de "criminalização". Ainda que a legislação educacional preserve a construção de um pensamento crítico e democrático, as inúmeras investidas do movimento denominado Escola sem Partido provocaram tensões às práticas educacionais com essa temática, ao considerá-la como "doutrinação política e ideológica na sala de aula" e "usurpação do direito dos pais sobre a educação moral e religiosa de seus filhos". 6

Soma-se a isso, grupos religiosos que a partir da terminologia "ideologia de gênero", gramática gestada no seio da Igreja Católica, operacionaliza uma "contraofensiva político-discursiva poderosa contra o feminismo e sua proposta de reconhecimento e avanço em matéria de direitos sexuais e reprodutivos" (MISKOLCI; CAMPANA, 2017, p. 726). Em escala global, tais setores religiosos convocam o combate a essa "ideologia" a favor da família tradicional, deturpada por políticas de governos de esquerda (cf. MISKOLCI \& CAMPANA, 2017).

Flávia Biroli (2018) destaca que a discussão de gênero e raça no Plano Nacional de Educação é fundamental não apenas para reduzir a discriminação, mas sobretudo o sexismo, o racismo, a violência contra mulher e a homofobia. A ofensiva contra essa pauta está articulada em torno da dimensão ideológica da "defesa da família" que funciona como uma espécie de "guarda-chuva" na dinâmica atual, com convergência da agenda moral e da agenda de segurança pública, sob o escopo do neoliberalismo.

Ainda para a autora, a aliança entre esses grupos conservadores corresponde a uma sustentação ideológica que articula a concepção restrita de arranjos familiares e a seletividade da proteção à infância, preservando direitos de alguns e lançando outros à violência do Estado. Não por acaso, a criminalização e o encarceramento são elementos importantes para política de controle dos corpos, "em que o apagamento de experiências

Doméstica durante a pandemia do COVID-19, elaborado pelo Fórum Brasileiro de Segurança Pública, publicado em 20 de abril de 2020. Disponível em http://forumseguranca.org.br/wpcontent/uploads/2018/05/violencia-domestica-covid-19-v3.pdf

5 Sobre a disputa política entre grupos conservadores no Congresso Nacional, ver Soares, 2013.

${ }^{6}$ Site Escola sem partido: https://www.escolasempartido.org/ 
e identidades é o subtexto de muitas proposições, num espectro que vai do Estado da Família às propostas em tramitação para a redução da maioridade penal no país" (BIROLI, 2018, p. 164). Isso deságua na estratégia da escola sem partido em considerar "ensino partidário" qualquer ação da educação que priorize os princípios de justiça social, do antirracismo, da igualdade e da valorização da diferença.

Nesse ínterim, o currículo escolar ganha ainda mais centralidade na disputa política histórica de diversos grupos sociais, endossando a "Pedagogia do armário", um conjunto de práticas, relações de poder, hierarquizações, privilégios, construções de saberes e desigualdades que tendem a construir um currículo pautado nas normas de gênero e da matriz heterossexual (cf. JUNQUEIRA, 2013). Assim, a heteronormatividade, nas palavras do autor: "está na ordem das coisas e no cerne das concepções curriculares". E, seguindo essa lógica, a escola se apresentaria como uma instituição: "fortemente empenhada na reafirmação e na garantia do êxito dos processos de heterossexualização compulsória e de incorporação das normas de gênero, colocando sob vigilância os corpos de todos (as)" (JUNQUEIRA, 2013, p. 483).

As tensões provocadas por essa "criminalização" de práticas pedagógicas que problematizam as questões de gênero inviabilizam possibilidades de enfrentamento de um problema estrutural da realidade brasileira: a violência contra a mulher. Apesar do avanço dos instrumentos de prevenção e de enfrentamento dispostos na legislação brasileira - Lei Maria da Penha (Lei n. ${ }^{\circ} 11.340 / 2006$ ), Lei do Feminicídio (Lei $\mathrm{n}^{\mathrm{o}}$ 13.104/2015), Lei da Importunação Sexual (Lei n ${ }^{\circ} 13.718 / 2018$ ) - os índices ainda nos posicionam no $5^{\circ}$ lugar do ranking mundial de violência contra a mulher (cf. WAISELFISZ, 2015). Esses dados também revelam que a violência atinge de forma desproporcional as mulheres conforme a combinação de múltiplas formas de discriminação de gênero, raça, etnia, classe, orientação sexual e identidade de gênero.

As graduais derrotas dos últimos anos, na prevenção e enfrentamento da violência de gênero, sobretudo com o corte de investimentos do governo federal durante o ano de 2019, se materializam no aumento alarmante dos números das agressões durante a pandemia do COVID-19. O isolamento social imposto pela pandemia radicaliza as condições históricas e estruturais das desigualdades de gênero, situação que não se restringe ao Brasil. Além da sobrecarga do trabalho doméstico e das tarefas do cuidado, as mulheres estão diante de inúmeras situações de vulnerabilidades e violências. Ainda que tenhamos que considerar que a pandemia impacta as mulheres de formas diferentes - a depender de classe, raça, geração, localidade, dentre outros aspectos - o fato é que a convivência forçada num ambiente familiar, por muitas vezes restrito, expõe ainda mais as mulheres aos seus agressores. Associa-se a esse quadro, a dificuldade de enfrentar essa situação de violência diante de um contexto em que os canais de denúncia e de proteção estão restritos.

Essa condição de intensificação da violência contra mulher em tempos de crise evidencia a urgência do debate de gênero na escola e a posiciona como espaço potente de contradições que podem engendrar transformações. Abre-se à produção de processos de ensino e aprendizagem que "desestabilize as verdades", rompa com as naturalizações e construa um processo educativo que desenvolva capacidade crítica e resistência às variadas formas de opressão.

E, nesse sentido, nossos fazeres científico e pedagógico se enquadram, de um ponto de vista epistemológico, no âmbito Linguística Aplicada Indisciplinar (cf. MOITA LOPES, 2006) ou de uma Linguística Aplicada Transgressiva, como defende Pennycook 
(2006). Sob tais perspectivas, buscamos colocar em pauta a construção de um saber a partir de um diálogo entre um saber da e sobre a linguagem com as ciências humanas, de modo a entretecer uma trama (ou um nhanduti) entre essas áreas do conhecimento. Por um viés mais operacional, nosso fazer encontra guarida nos estudos em tornos dos (multi)letramentos, exatamente por proporcionar a participação das/os alunas/os nesse enredamento, valendo-se de práticas sociais de leitura e escrita, de maneira ética, crítica e democrática (cf. ROJO, 2009).

Em especial, por buscarmos reler o contexto fronteiriço de nossa atuação, a intervenção pedagógica buscou privilegiar a cultura local, o entorno e as identidades da fronteira para, num processo de deglutição e problematização da diferença, assumir uma postura autoral frente à leitura e produção dos textos. Esse voltar-se para o entorno buscou inspiração no Grupo Nova Londres e sua pedagogia dos multiletramentos, preconizados por Cope e Kalantzis (2009). Desse modo, ler e discutir sobre a violência contra a mulher passaria, também, por pensar o aqui-agora, da fronteira do Brasil/Paraguai, onde estávamos inseridos, contexto esse marcado pela interculturalidade, no dizer de García Canclini (2009).

\section{O contexto da geração dos dados e categorias de análise}

Como já mencionado, o material objeto de análise deste texto foi gerado a partir da experiência pedagógica de um projeto extracurricular denominado "Oficina de Textos e Ideias", no Instituto Federal de Mato Grosso do Sul (IFMS), campus Ponta Porã. ${ }^{7}$ Dentre as atividades desenvolvidas por esse projeto, realizamos a sequência de atividades, entre os anos de 2014 e 2015, intitulada "Igualdade de gênero na diversidade dos gêneros" para participar do Concurso $10^{\circ}$ Construindo a Igualdade de Gênero. Sendo, portanto, a produção documental gerada a partir desse processo, torna-se plausível que o relato de experiência preceda a análise documental.

Esse campus apresenta uma particularidade: está localizado numa fronteira seca com Paraguai, avizinhando-se, sem nenhum obstáculo geográfico, com o município paraguaio de Pedro Juan Caballero, sendo, portanto, ambas, cidades-gêmeas, como poucas que existem no Brasil. Ao andarmos pelas ruas de Ponta Porã ou Pedro Juan, não localizamos de imediato onde termina um país e começa o outro. Essa proximidade proporciona que grande parte das escolas do município de Ponta Porã, em especial o IFMS, seja composta por estudantes de origem paraguaia. À primeira vista, a ideia que se sobressai é a de integração e complementaridade entre as duas nações, entre duas culturas. No entanto, essa proximidade traz consigo a problemática dos conflitos explícitos ou não - do contato/convívio/respeito com toda diversidade inerente em um cenário como esse.

Por sua vez, o ambiente escolar está atravessado por essas experiências cotidianas marcadas pelos dilemas da interculturalidade, à medida que expressa um contexto social, econômico, cultural e plurilinguístico (português, espanhol e guarani) muito complexo, exigindo da escola uma postura desafiadora para a gestão da diversidade local. Trata-se um universo plural que exige ser tratado em sua totalidade,

\footnotetext{
${ }^{7}$ O campus do Instituto Federal de Mato Grosso do Sul iniciou suas atividades em 2011 e oferece cursos técnicos integrados ao ensino médio; técnicos subsequentes nas modalidades presencial e à distância; e superiores, sendo que contava, na ocasião, com cerca de mil estudantes matriculados.
} 
permeado por uma rotina que goza de microrrelações constantes e infindavelmente dinâmicas, que antecedem a definição territorial e caracterizam a fronteira.

Considerados esses aspectos, o caminho encontrado foi pensar práticas de letramentos por intermédio de um projeto pedagógico que fosse capaz de privilegiar e apreender a diversidade local em relação às questões de gênero e suas interseccionalidades, em especial, da violência contra a mulher, e, consequentemente, a construção de um posicionamento crítico sobre suas formas de opressão que se formam nas bordas da fronteira.

Diante do desafio de promover a participação dos envolvidos no concurso promovido pela Secretaria de Política para as Mulheres, elaboramos a sequência de atividades que estimulasse os participantes a produzirem textos sobre temática. A proposta tinha como premissa dois momentos intercambiantes: um teórico, de compreensão das questões feministas; e outro mais literário, de fruição, via diferentes códigos semióticos. Logo, a partir do mote "gênero na diversidade dos gêneros", sintetizou-se a proposta: discutir gênero a partir dos mais diversos gêneros textuais, mediando atividades significativas de leitura e escrita.

A oficina ocorreu a partir do segundo semestre de 2014 e se estendeu até primeiro trimestre de 2015, com a participação de 22 alunas/os do segundo, quarto e sexto períodos dos cursos do Ensino Técnico Integrado ao Médio em informática e em agricultura. Decidiu-se, entre as/os participantes do projeto, desenvolver as atividades para auxiliar no desenvolvimento do produto final: um texto para participar do concurso. Com isso, criou-se uma motivação para a escrita. Pensou-se em realizar atividades que dessem conta de dois propósitos: a discussão teórica de questões ligadas à igualdade de gênero e a fruição a partir de textos literários. Assim, conforme demonstrado no Quadro 1, procuramos utilizar um conjunto de material diversificado, como crônicas, contos, (mini)contos, poemas, dados da violência contra mulher, filme e canções, textos sobre pensadoras feministas, depoimentos de mulheres e textos científicos.

Quadro 1: Abordagem didática

\begin{tabular}{|c|l|l|}
\hline Encontro & \multicolumn{1}{|c|}{ Gênero textual, título e autoria } & \multicolumn{1}{|c|}{ Estratégia didática } \\
\hline $1^{\circ}$ & $\begin{array}{l}\text { Conto finalista do Prêmio Igualdade de Gênero - } \\
\text { 2013: "Mulher Itacira, rasgando desigualdades", } \\
\text { de Tairine Oliveira. }\end{array}$ & $\begin{array}{l}\text { Leitura compartilhada do texto e } \\
\text { apresentação do concurso. }\end{array}$ \\
\hline $2^{\circ}$ & $\begin{array}{l}\text { Texto sobre Simone de Beauvoir disponível em: } \\
\text { O LIVRO DA POLÍTICA. As grandes ideias de } \\
\text { todos os tempos. Trad. de Rafael Longo. São } \\
\text { Paulo: Editora Globo, 2013. }\end{array}$ & $\begin{array}{l}\text { Leitura silenciosa e roda de } \\
\text { conversa sobre o texto. }\end{array}$ \\
\hline $3^{\circ}$ & $\begin{array}{l}\text { Conto: "A moça tecelã", de Marina Colasanti } \\
\text { (Minicontos de Marina Colasanti) } \\
\text { Artigo: RONQUI, Ângela. Simone; ALVES, } \\
\text { Regina. Célia. Santos. A representação da } \\
\text { violência contra a mulher em contos de Marina } \\
\text { Colasanti. Ipotesi (UFJF), v. 13, p. 127-133, } \\
\text { 2009. }\end{array}$ & $\begin{array}{l}\text { Leitura compartilhada e exploração } \\
\text { docursos expressivos } \\
\text { dos }\end{array}$ \\
\hline
\end{tabular}




\begin{tabular}{|c|c|c|}
\hline $4^{\circ}$ & $\begin{array}{l}\text { Poemas: "Poema das Sete Faces", Carlos } \\
\text { Drummond de Andrade; "Com licença poética", } \\
\text { Adélia Prado. } \\
\text { Letras/canções: "Até o fim", Chico Buarque; } \\
\text { "Pagu", Rita Lee; "A mulher e o mar", de Dorival } \\
\text { Caymmi. } \\
\text { "Uma singela mulheragem", e-mail em } \\
\text { homenagem ao dia das mulheres. }\end{array}$ & $\begin{array}{l}\text { Fruição e deleite dos poemas e } \\
\text { canções. } \\
\text { Análise da intertextualidade como } \\
\text { fator de textualidade. }\end{array}$ \\
\hline $5^{\circ}$ & Projeção do Filme: "Flor do deserto" & $\begin{array}{l}\text { Proposta para escrita de uma breve } \\
\text { resenha. }\end{array}$ \\
\hline $6^{\circ}$ & Produção Resenha do filme. & $\begin{array}{l}\text { Roda de conversa sobre o filme e } \\
\text { socialização das resenhas. }\end{array}$ \\
\hline $7^{\circ}$ & $\begin{array}{l}\text { Depoimentos de experiências e trajetórias } \\
\text { pessoais de mulheres }\end{array}$ & $\begin{array}{l}\text { Escuta dos depoimentos de } \\
\text { mulheres e espaço interlocução com } \\
\text { suas experiências. }\end{array}$ \\
\hline $8^{\circ}$ & $\begin{array}{l}\text { Crônica: "Lágrimas e testosterona", de Moacyr } \\
\text { Scliar. }\end{array}$ & $\begin{array}{l}\text { Exploração de recursos da narrativa } \\
\text { e do conceito de estereótipos de } \\
\text { gênero que perpassa a crônica. }\end{array}$ \\
\hline $9^{\circ}$ & $\begin{array}{l}\text { Artigo científico: PISCITELLI, Adriana. } \\
\text { Gênero: a história de um conceito. In: ALMEIDA } \\
\text { \& Szwako. Diferenças, Igualdade. São Paulo: } \\
\text { Berlendis \& Vertecchia, 2009. }\end{array}$ & $\begin{array}{l}\text { Leitura e discussão sobre a } \\
\text { categoria analítica Gênero. Divisão } \\
\text { em grupos e socialização das } \\
\text { leituras. }\end{array}$ \\
\hline $10^{\circ}$ & $\begin{array}{l}\text { Mapa da Violência contra Mulher } \\
\text { WAISELFISZ, Julio. Jacobo. Mapa da violência } \\
\text { 2012: Atualização Homicídio de Mulheres no } \\
\text { Brasil. São Paulo: Flacso, 2012. }\end{array}$ & $\begin{array}{l}\text { Leitura crítica } \text { dos dados } \\
\text { estatísticos, com destaque para } \\
\text { Ponta Porã-MS, } 12^{\circ} \text { no ranking } \\
\text { nacional. }\end{array}$ \\
\hline $11^{\circ}$ & Exposição oral dos projetos de texto. & $\begin{array}{l}\text { Organização em grupos para } \\
\text { discussão dos projetos de textos a } \\
\text { serem produzidos e socialização das } \\
\text { ideias. }\end{array}$ \\
\hline $12^{\circ}$ & $\begin{array}{l}\text { Textos colaborativos. Exposição oral sobre os } \\
\text { textos em produção. }\end{array}$ & $\begin{array}{l}\text { Apresentação da plataforma digital } \\
\text { Wikispace. } \\
\text { Escuta dos processos criativos, } \\
\text { sugestões. }\end{array}$ \\
\hline $13^{\circ} 14^{\circ}$ e $15^{\circ}$ & Textos produzidos pelos participantes & $\begin{array}{l}\text { Início do processo de revisão dos } \\
\text { textos e digitação para postagem no } \\
\text { sítio do concurso. }\end{array}$ \\
\hline
\end{tabular}

Fonte: Os autores.

Foram propostos encontros semanais e, ao final de cada encontro, um participante da oficina ficaria responsável por fazer o registro num caderno, um diário de bordo. Nesse diário, a linguagem escolhida para o registro ficaria à mercê das/os 
participantes, podendo ser escrita ou imagética, ou contemplando ambas. O importante seria registrar, de algum modo, a percepção do participante naquele dia.

Os dois momentos do projeto (teórico e literário) se desdobram em atividades desenvolvidas em duas frentes distintas: uma de provocação para a escrita, em que foram lidos e discutidos os textos selecionados sobre gênero, desigualdades e violências; e outra de escrita e revisão dos textos produzidos pelas/os alunas/os. Nessa segunda etapa, utilizamos a plataforma Wikispace, como uma forma de romper com a hierarquia entre professor e alunas/os, colocando todas/os as/os participantes como sujeitos que interagem e opinam sobre produtos da escrita, inclusive no meio digital atendendo à proposta dos letramentos novos. Buscou-se construir um posicionamento de que, embora estivessem participando de um concurso, eram uma equipe com um propósito em comum - que é exatamente pensar sobre o outro - logo, não haveria sentido em ver o colega como um concorrente.

Os resultados da ação foram significativos. Os textos refletiram, em grande parte, a construção da identidade da mulher sob um viés múltiplo e interseccional. Além de que, pela apreensão de trechos dos textos literários produzidos, ficou evidente a construção de um discurso de combate à violência contra a mulher, como veremos a seguir.

Antes, cabe informar que dos 22 participantes da oficina, nove deles enviaram texto final para o concurso, sendo sete alunas e dois alunos. A participação era voluntária, sendo que alguns deles não terminaram o texto no prazo hábil para a submissão ou simplesmente preferiram não participar. Não obstante a submissão do texto, acreditamos que a vivência no processo teve resultados profícuos na construção de um posicionamento pró igualdade de gênero, bem como em razão da participação nas atividades da oficina.

O quadro a seguir apresenta o título dos textos e uma sigla pela qual nos referiremos ao texto, durante a análise. Por questões éticas, optamos por não referenciar os autores dos textos.

Quadro 2: Títulos dos textos analisados

\begin{tabular}{|c|c|}
\hline SIGLA & TÍTULO \\
\hline T1 & Sonhos adormecidos \\
\hline T2 & Escolha, consequência e julgamento \\
\hline T3 & Ama vida em mascaras \\
\hline T4 remissão da trapezista \\
\hline T5 & O que eu não consigo esquecer \\
\hline T6 & Um desnecessário rito de passagem \\
\hline T7 & Menina de casa \\
\hline T8 & Harmonia gerada pelo perdão e gentileza \\
\hline T9 & Mulher mbarete \\
\hline
\end{tabular}


Fonte: Os autores

A partir desses textos, estabelecemos seis categorias de análise que sobressaíram de nossa leitura dos textos, sendo elas:

(i) autopercepção sobre a necessidade de se romper com o silêncio;

(ii) problemática da culpabilização da mulher sobre os atos de violência;

(iii)naturalização da violência contra a mulher;

(iv)aparecimento de matizes da cultura local, em especial ligados às identidades;

(v) desconstrução de estereótipos sobre os papéis de gênero;

(vi) ressignificação da violência sofrida.

\section{Igualdade de gênero nos textos produzidos}

O movimento de análise partiu da seleção de recortes significativos, capazes de ilustrar a apropriação de um discurso em prol a igualdade de gênero e, em especial, de combate à violência contra a mulher, tendo como foco as seis categorias apontadas anteriormente.

A constatação do sofrimento da violência implica um posicionamento responsivo no combate a ela. Muitas vezes, o agir do agressor é dotado de tanta opressão que a agredida custa a perceber ou tem a visão da realidade tão eclipsada pelo domínio masculino, que o silêncio é o único refúgio onde se abrigam.

Jamais cogitei em contar a alguém, mesmo nos momentos em que a dor mais me testou. (T4) [grifo nosso]

A reação à violência, ao romper com o silêncio, implica em se deslocar em direção à reconfiguração das relações de poder em que muitas identidades marginalizadas podem, enfim, "tornar-se sujeito" ao definir suas realidades, estabelecer suas identidades e nomear suas histórias (cf. KILOMBA, 2019). E como sugere bell hooks (2019, p. 96), sendo essa violência patriarcal, sua supressão "exige desafiar e mudar maneiras fundamentais de se pensar gênero" e ter como pauta o fim de todas as formas de violência.

Em outro texto, uma das alunas refere-se a um episódio em que a informação veiculada pela televisão serve para esse despertar sobre a situação de violência e, consequentemente, uma tomada de posição:

..então viu a marca roxa em seu braço, no mesmo momento lembrou das histórias daquelas mulheres, e em seguida, teve vários flashes de sua vida com seu "querido", cada briga e desentendimento. De repente os "incidentes" que ela perdoou e passou por cima tão facilmente pareceram muito maiores e frequentes do que ela achava, ela pensou muito em sua história e se perguntou se ele realmente a amava, ficou desesperada e sem saber se tinha razão decidiu então ir conversar com uma amiga... (T1)

O falar sobre a violência, no excerto a seguir, nos chega pelo compartilhar a partir de uma escuta amiga, entre irmãos, a vítima guardou silêncio sobre a violência praticada por um colega do irmão. Apresenta-se, no trecho, como alguém que tem superado o silenciamento, encorajando-se para compartilhar sobre a violência sofrida, mesmo que não recorra à queixa criminal. Interessante apontar que o autor do texto é 
um aluno, pode-se dizer que, possivelmente, haja uma sensibilização para a escuta com a qual o aluno-autor, sendo adolescente do sexo masculino, se identifica, como agente, também, de combate à violência.

Ele [o irmão] me entendeu, e ficou muito emocionado, assim como eu. Naquele dia, eu me senti renovada, porque, mesmo não tendo denunciado, eu pelo menos consegui contar para alguém, era muito difícil para mim! (T5)

Outro trecho coletado na amostra, vem de uma escrita de si em que a aluna faz um relato pessoal de violência sofrida por parte do seu então namorado, logo nos primeiros anos da adolescência. Esse encorajamento precedeu a escrita do texto, uma vez que, no sétimo encontro das oficinas, contamos com a presença de mulheres da comunidade local para testemunharem sobre o processo de sua constituição como mulher. Nesse dia, após ouvir os relatos, a estudante compartilhou com o grupo o seu caso. No trecho que segue, ela detalha como percebeu a violência sofrida e como se desperta para um olhar crítico sobre práticas machistas cotidianas, estreitamente atreladas a um modus operandi esperado pelo estereótipo do sujeito macho.

A coragem que criei para poder contar essa história vem sendo preparada desde quando estive trancada em casa, porque foi quando comecei a perceber que não podia mais viver nisso, com todo esse pesadelo real rondando o tempo todo em minha cabeça. Não podia mais viver com todas aquelas falas machistas que todos falam. "Ele é menino." "É normal." "É só uma fase." "Ela 'deu' porque quis." "Ela pediu." (T6)

Os excertos anteriores tematizam o dilema entre o guardar e o romper do silêncio. Eles são sintomáticos da apropriação de um saber que coloca a mulher no papel de sujeito, cujo silêncio por tanto tempo guardado precisa ser rompido, valendo-se dos órgãos legais instituídos para tal, inclusive delegacias especialmente para mulheres e por elas geridas, bem como outros ganhos legais formalizados na Lei 11.340/06, conhecida como Lei Maria da Penha. Ganhos esses que problematizam as violências, num país onde a agressão foi (e ainda é), historicamente tratada como algo natural, inerente ao homem que detém a propriedade sobre a mulher.

Um agravante para romper com o silêncio pode residir no sentimento de culpa que a própria vítima sente. Santos e Izumino (2005) ao historicizar as políticas de combate a violência contra a mulher, citam Soares (2002) que prefere o uso da expressão "mulheres em situação de violência", pois ainda que elas "não sejam 'vítimas', a vitimização ainda se trata de um instrumento necessário para a sensibilização dos agentes do Estado, os quais tendem a 'culpabilizar' as mulheres em situação de violência e não veem violência contra as mulheres como um crime" (SANTOS e IZUMINO, 2005, p.160). Essa crença de culpabilização da mulher é tão grande, haja vista que o Estado assim o faz, que até mesmo as vítimas não se reconhecem como tal. Os textos dos participantes da oficina, em certa medida, apontam para isso:

Muitos a chamavam de burra e até a culpavam. Ao receber esses julgamentos, Linda se culpava ainda mais. É certo que ela não queria passar por aquilo, mas o amava e não conseguia deixar de amar mesmo que quisesse. (T2) [grifos nossos] 
A culpa, no trecho acima, tem sua gênese no olhar que os outros lançam para a vítima. É reflexo de uma relação de poder, que desloca a culpa do agressor e concentra na vítima, exigindo dela uma postura firme que fosse capaz de evitar a violência, por isso era chamada de "burra", que se deixou agredir. Outro modo de aparecer a culpa vem pela vergonha da exposição e, consequentemente, da avaliação que os outros possam fazer, como se a mulher tivesse condições de impedir o ato em si e, se houve a violência, seria por ter possibilitado, como se vê no trecho que segue.

Naquela noite, não voltei para casa. Sentia-me culpada e envergonhada, mais do que intimidada pela presença de meu padrasto. Como pudera eu, agir com tamanha falta de respeito por minha família? Porém, assim que os primeiros raios de sol surgiram no horizonte, voltei. A primeira coisa que fiz, mecanicamente, foi lavar minha saia ensanguentada. Em seguida, caí no sono. Acordei somente quando minha mãe começou a me bater com uma cinta, por eu ter passado a noite fora e por não ter feito o almoço de Melquíades. (T4) [grifos nossos]

Como a mulher é sempre culpabilizada, até sobre o destino de seus rebentos the atribuem a culpa. No excerto seguinte, novamente o olhar dos outros, inclusive outras mulheres, lançam a culpa sobre ela. Há recorrência, inclusive, às crenças populares para justificar a culpa. Percebe-se um movimento de silenciar a dor, fomentar um sofrimento solitário.

O primeiro filho que tivemos nasceu morto. E, de todas as vezes que a família de meu marido me repudiou, esta foi a mais dolorosa. Culpavam-me pela morte da criança, minha sogra e suas filhas - diziam que eu não devia ter feito os serviços domésticos (que elas próprias me ordenavam a fazer) ao longo da gestação, diziam que de nada me servia ter as ancas largas. Elas disseram, também, que se eu chorasse no enterro, acabaria molhando as asas do anjinho e ele não conseguiria subir aos céus. Não chorei, mas quase tirei-me a própria vida. (T4) [grifos nossos]

Já no trecho de T6, novamente na escrita de si, vemos também a culpabilização, justificada pela crença na descoberta de um modo natural do homem agir. Modo esse que precisaria ser entendido pela vítima, logo, não caberia queixa:

Eu me culpei pelo acontecido, mesmo não entendendo direito a situação. Pensei que fazia parte da natureza dele agir assim, ou seja, eu como namorada dele tinha a obrigação de fazer o que ele quisesse, mesmo que isso me machucasse. Não parava de pensar que eu poderia ter evitado aquilo, e por isso a culpa foi toda minha. Porque eu não tomei atitude? Não evitei? (T6)

Como aponta Saffioti (1997), o caso da violência masculina contra a mulher gera silenciamentos que precisam ser considerados como resultantes de relações sociais violentas. Para a autora, não há cumplicidade da mulher porque ela não compartilha da estrutura de poder da organização social de gênero. É o homem quem tem o poder de decidir a situação de vida ou de morte sobre a mulher, que diante disso, desfruta de parcelas de poder bem menor para mudar a situação. Para que ela pudesse estar em 
condições de consentir com violência masculina, seria necessário ocupar a mesma posição de seu parceiro nessa estrutura de poder.

A aluna-autora de T9, a seguir, sensibiliza o leitor sobre a culpabilização da mulher como prática cotidiana. Para isso, faz remissões intertextuais a vozes que circulam e são parte de um imaginário coletivo que naturalizam a atribuição da culpa da própria mulher sobre a violência sofrida.

Mas, infelizmente, nesse caso, só há umas justificativas extremamente particulares e falocêntricas: "Ela pediu, e no fundo no fundo, merecia!", "eu quis, e garanto que ela gostou.", “então, não nascesse mulher se fosse para reclamar". E isso sangra. (T9) [grifos nossos]

Seguindo o mesmo viés realista de retratar esse conjunto de vozes, a autora de T9 demonstra o traquejo para denunciar a naturalização da violência, temática abordada na oficina, especialmente quando da leitura do Mapa da Violência (WAISELFISZ, 2012), cujas fatídicas cifras sobre o município nos impulsionou a discussão. Essa naturalização é perceptível nos dois trechos que seguem:

As pessoas que acompanhavam de perto apenas olhavam, por pura curiosidade, até porque “em briga de marido e mulher não se mete a colher". E como ironia machadiana: a anulação quanto mulher para desenvolver seu papel social quanto mãe, e essa mesma mãe foi anulada pelo seu próprio progênito que se preocupou apenas com seu pai, o homem de H maiúsculo da história. “¡Y se acabó!?”. (T9) [grifos nossos]

A aluna vale-se da expressão popular para legitimar o imaginário, demonstrandoo com certa ironia; faz, inclusive, uma intertextualidade implícita com a obra de Machado de Assis, conhecido por retratar cenas de violência em razão de adultério. Fica evidente a apropriação de um conteúdo de literatura do ensino médio, sendo, aqui, utilizado com força argumentativa para a construção de uma cena de desigual disputa e consequente vitória do macho, "o H maiúsculo da história".

Mais adiante, relata a chegada de um policial ao local do crime e seu tratamento de indiferença estratégica. O Estado opressor é aqui representado pelo policial, com um agente que não reconhece o crime em questão, já que se trataria de "só" mais uma briga de marido e mulher.

Direcionou sua voz impaciente - como se estivesse ali só para cumprir horário e ganhar seu salário ao final do mês -e soltou aquela pergunta retórica que indicava maus presságios: "Você apanhou de seu marido?".E, com um ar de extremo machismo, tocou em seu queixo e a arremessou para o lado, como se fosse apenas uma peça de objeto. Foram os doze segundos de escravidão feminina mais indescritível a qualquer linguagem corporal e/ou gramatical. (T9) [grifos nossos]

Além da indiferença verbal, com a pergunta, há um gesto, o tocar no queixo seguido do arremesso para o lado, que corporalmente encarna esse sentimento. $O$ desenrolar da cena vem ao encontro do que defende Minayo (2005, p. 24), para quem "o masculino é investido significativamente com a posição social (naturalizada) de agente do poder da violência, havendo, historicamente, uma relação direta entre as concepções 
vigentes de masculinidade e o exercício do domínio de pessoas, das guerras e das conquistas".

Outro aspecto relevante da intervenção por meio das oficinas foi de privilegiar aspectos da cultura local, no caso, da fronteira. Como nós, os professores, não éramos do estado, tampouco da fronteira, e dado nosso envolvimento com questões linguísticas e sociológicas, havia um certo encantamento com a diversidade local. Algo que não era compartilhado com os fronteiriços. Aos poucos, fomos desenvolvendo (em nós) um pertencimento com a cultura local e um reconhecimento como parte dela, os quais sempre buscamos levar para a sala de aula.

Ao tratarmos da mulher na fronteira outras identidades entraram em cena para dar conta desse espaço poroso e intercultural. A fronteira é locus privilegiado do que García Canclini (2009, p. 17) defende como interculturalidade, pois ela "remete à confrontação e ao entrelaçamento, àquilo que sucede quando os grupos entram em relações e trocas". Tal concepção se opõe ao multiculturalismo como espaço de aceitação da heterogeneidade; a interculturalidade, antes, "implica que os diferentes são o que são, em relações de negociação, conflito e empréstimos recíprocos".

Nesse nhanduti, como dito no início, outras culturas ganharam corpo de mulher nos textos das/os alunas/os e, com isso, refletiram parte da interculturalidade da fronteira, bem como suas tensões.

\begin{tabular}{|c|l|}
\hline Mulher indígena & $\begin{array}{l}\text { Índia, morena, dos olhos cor de mel, pela maioria da população sou } \\
\text { considerada de altura baixa, me chamo Claudina. Por enquanto } \\
\text { somente uma criança, mas me vejo como uma adulta. Filha de uma } \\
\text { branca que se encontrava as escondidas com um índio, pelo o que } \\
\text { vovó disse era "paixão calorosa, algo de momento", nunca entendi } \\
\text { ao certo o que ela quisera me dizer com isso e nem faço questão } \\
\text { (T3) }\end{array}$ \\
\hline Mulher paraguaia & $\begin{array}{l}\text { Un cabelo loiro, olhos pequenos tanto quanto de indígenas, e um } \\
\text { marbio que não deixava fugir sua nacionalidade paraguaia. "Muy } \\
\text { condução de energia, pedindo socorro, em silêncio. Tentava nos } \\
\text { explicar, com aquele sotaque de guarani embalando seu portunhol, o } \\
\text { quão difícil era denunciar aquele homem. (T9) } \\
\text { (..) } \\
\text { Dessa maneira, eu cresci ouvindo - sem entender - que só há um } \\
\text { aspecto mais desprezível do que ser uma mulher: é ser uma mulher } \\
\text { paraguaia. (T9) }\end{array}$ \\
\hline Mulher cigana & $\begin{array}{l}\text { Nasci sobre as lonas sujas de um circo, cuja estrutura era sempre } \\
\text { desmontada às pressas para fugir de homens que - ao notarem que } \\
\text { as pepitas de ouro que lhes foram vendidas pelos ciganos da trupe } \\
\text { eram, na verdade, despiciendas pedrinhas - perseguiam, } \\
\text { enfurecidos, as carretas onde viajávamos. (T4) }\end{array}$ \\
\hline Mulher imigrante & $\begin{array}{l}\text { Buscando novos voos, em um país que genericamente chamado de } \\
\text { China, a família deixou sua terra natal, Taiwan. (T8) }\end{array}$ \\
\hline
\end{tabular}


A índia e a paraguaia parecem revelar-se como conjunto de opressões e violências que marcam os corpos femininos, em que a segunda é por consequência da primeira. A menina relatada pela autora do T5 é fruto de uma violência sexual, com matizes coloniais, interpretada pela avó da narradora, por um viés da naturalização da violência aos moldes de Iracema, como uma "paixão calorosa, algo do momento". Já a paraguaia, nos chega pelos traços indígenas, somados à referência ao sotaque, ao portunhol, como marca do repertório linguístico local.

Abrindo parênteses, com vistas a complementaridade, especificamente sobre as línguas da fronteira, a autora do T9 problematiza, na narrativa, o preconceito linguístico (BAGNO, 2002):

Minha avó materna contava-me sobre o tempo em que a língua guarani transformou-se em "vergonha guarani", e com esse horizonte, as mulheres não puderam ter continuidade de conduzir todos os ensinamentos de uma raiz cultural para seus familiares, perdendo, assim, uma das únicas e restritas utilidades femininas. (T9) [grifos nossos]

O trecho é revelador do apagamento da diversidade por meio de uma política linguística familiar, recorrentemente relatada no cotidiano da fronteira. Interessante que, mais uma vez a autora lança um olhar irônico sobre o papel estereotipado da mulher, como sendo aquela que deve ser a responsável pelo ensino na casa. Fechamos os parênteses para tratar das outras identidades que aparecem.

$\mathrm{O}$ aparecimento da cultura cigana mostrou-se como um caso não endêmico da fronteira, haja vista que se trata de populações nômades, entretanto, chama-nos a atenção exatamente pelo processo de escrita do texto. $O$ enredo são memórias da avó da aluna-autora, ela é narradora. O conteúdo que inspirou foi acessado pela atividade da oficina, a mesma dos relatos, em que a familiar foi até a reunião e ali fez um relato, emocionado e emocionante, de sua trajetória no circo e entre os ciganos. Outro aspecto que chama atenção, em razão do repertório cultural e letramento literário da aluna, o nome dado ao agressor, Melquíades, cigano, como o personagem de Gabriel Garcia Marques, pelo qual a aluna nutria grande admiração e com qual teceu essa intertextualidade.

Por sua vez, a mulher imigrante taiwanesa aparece pelo fato de que o alunoautor, sendo também imigrante, traz a história da adaptação de sua família ao Brasil. O fato é revelador do grande fluxo de orientais na fronteira, especialmente em razão das atividades comerciais no país vizinho.

Tais exemplos, como já mencionado no início, demonstram um fazer pedagógico pautado nos multiletramentos, já que aspectos da cultura local são, no âmbito das oficinas, problematizados e incorporados na produção textual dos participantes. Ademais, acreditamos que nossa prática vai ao encontro do que Maher (2007) defende sobre a educação do entorno para a interculturalidade. Por seu turno, centrada na educação bilíngue indígena, a autora refere-se à necessidade de formar os não índios para o diálogo intercultural, a fim de fortalecer politicamente a causa indígena. A mesma lógica pode se aplicar ao nosso caso, pois a escola da fronteira, ao trazer temas ligados à igualdade de gênero e à diversidade local, fortalece o combate à desigualdade e todas as formas possíveis de violências.

Mais um ponto percebido na leitura dos textos foram os estereótipos sobre papéis essencialmente masculinos ou femininos que, na narrativa, foram problematizados 
pelas alunas-autoras. Dunker (2017) explica a etimologia do vocábulo estereótipo, do grego, stereo typos, que inicialmente seriam os tipos utilizados nos primórdios da imprensa. Assim, funcionariam como carimbos móveis que garantiriam a impressão em massa. O mesmo princípio seria aplicado a pessoas, reduzidas a tipos móveis. Mais que isso, amplia o psicanalista, estereótipos "são também discursos estereotipados que nos fazem sofrer por sua monotonia e que nos constrangem a deixar nossa palavra plena dentro da caverna de si” (DUNKER, 2017, p. 115). E como as pessoas sofrem em razão dos estereótipos atribuídos aos papéis sociais do homem e da mulher! O excerto que segue sugere uma problematização acerca da atribuição de afazeres domésticos às mulheres, como em:

Minha mãe nunca cozinhara bem e isso não era um problema até então. Mas passou a ser e, por sorte, quando meus irmãos não eram mais bebês. Pois eu - para evitar que Melquíades continuasse a espancá-la, por raiva de sua "inutilidade" - deixei de cuidá-los para fazer o almoço, a janta e suas respectivas entregas no local onde ele estivesse trabalhando - minha rotina configurou-se de modo a atingir as demandas do homem que mais me enojava. (T4) [grifos nossos]

O fato de mãe não se enquadrar no estereótipo, a tornava inútil para o padrasto. A narradora, em tenra idade, idade escolar, assumiria esse papel a serviço do seu algoz. $\mathrm{O}$ ato de estudar e frequentar escola, ainda no contexto de T4, era privilégio exclusivo dos meninos:

...meus irmãos - que passaram a frequentar a escola pela manhã, diferente de mim, que não tinha essa "necessidade" por ser do sexo feminino - vendiam tachos com meu padrasto durante à tarde, e eu fazia os serviços domésticos. (T4)

Crença essa cuja gênese remonta o período colonial e parte do republicano, marcado pela exclusão da mulher dos espaços de escolarização. Tamanha é a força desse posicionamento que sua reprodução é facilmente detectada na fala das gerações anteriores, como relatado em T6:

Meu pai e minha avó paterna eram contra a minha mãe continuar estudando, depois de ter me dado a luz. (T6)

E, quando a mulher chega à escola, sofre as coerções de outras facetas do estereótipo: ela precisa se diferenciar do homem por ser mais caprichosa, cuidadosa e aplicada... A escola torna-se, por excelência, um espaço generificado como apontado por Junqueira (2013) em sua discussão sobre "pedagogia do armário" e verbalizado por T7:

$\mathrm{Na}$ escola, assim como em todos os outros cenários, espera-se que as mulheres sejam delicadas e meigas, mas com relação específica à escola também exige-se que estas sejam mais esforçadas, estudiosas e que tenham até mesmo uma caligrafia dita como "de menina", mais correta e bela. (T7)

Os três excertos anteriores demonstram apropriação das estudantes sobre a constituição de uma violência que se naturaliza a agressão contra a mulher no imaginário dos grupos sociais. É preciso, portanto, buscar formas de desconstruir esse pensamento, um dos caminhos possíveis é recorrer a literatura, como nos textos de Marina Colasanti, Adélia Prado ( $3^{\circ}$ e $4^{\circ}$ encontros, respectivamente), utilizados durante as oficinas. Com muito humor, também pudemos vivenciar a desconstrução de estereótipos masculinos a 
partir da crônica "Lágrimas e testosterona" ( $8^{\circ}$ encontro), que ironiza com a falsa de ideia de que atributos biológicos do homem justificariam a violência como parte da virilidade.

Ao vincular a origem da opressão e exploração das mulheres ao sistema de produção e acumulação capitalista, o que implica reconhecer que ela não é cultural, Silvia Federici (2017) nos fornece importantes reflexões para pensarmos a posição social das mulheres, representada nos textos analisados. A reorganização da vida social capitalista desencadeia a construção de uma ordem patriarcal que mecaniza os corpos proletários, em especial, da mulher como máquina de produção de novos trabalhadores. Assim, "o corpo é para as mulheres o que a fábrica é para os homens trabalhadores assalariados: o principal terreno de sua exploração e resistência" (FEDERICI, 2017, p. $34)$.

Não por acaso, o surgimento do capitalismo coincide com a caça às bruxas, simboliza a guerra contra as mulheres e seu poder social e evidencia como a violência sobre os corpos femininos é constitutiva da nossa sociedade moderna. Dessa forma, apropriação dos corpos femininos pelo Estado e pelos homens se dá por sua demonização, estabelecendo formas públicas de controle pelo horror e pelo medo. Força-os a trabalhar, de forma não remunerada, dócil, obediente e silenciosa. Por isso, para muitas mulheres, o corpo pode ser tanto uma identidade quanto uma prisão.

Essas questões aparecem em vários fragmentos dos textos analisados, ao expor o silenciamento da dor e das violências: Sentia-me culpada e envergonhada, mais do que intimidada pela presença de meu padrasto" (T4); Não chorei (T4); Pensei que fazia parte da natureza dele agir assim (T6), então, não nascesse mulher se fosse para reclamar (T9); ao narrar a apropriação dos corpos femininos, escravidão feminina (T9) Culpavam-me pela morte da criança (T4), tocou em seu queixo e a arremessou para o lado (T9).

Na mesma esteira, a configuração da família nuclear e tradicional que se apropria, estrategicamente, do trabalho das mulheres, constrói identidades de masculinidade e feminilidade num projeto de dominação em que o patriarcado é fundamental para o capitalismo. Forja-se então o papel da mulher feminina como "função-trabalho", dona de casa, doméstica, no qual a reorganização do trabalho separa radicalmente as atividades consideradas masculinas e femininas e, concomitantemente, hierarquiza a relação de poder entre as duas formas. Oculta-se a produção pela perspectiva de um disfarce e/ou destino biológico que invisibiliza seu trabalho em nome da natureza e do amor maternal, portanto, conferindo-lhe um caráter gratuito. Gesta-se, assim, a sujeição econômica das mulheres aos homens ao retirar as condições de auto reprodução da vida, sendo a honra sua única propriedade (FEDERICI, 2017).

Destacamos como ponto recorrente nos textos analisadas o modo como a maioria deles foi finalizada. Em pelos menos seis deles foram apresentados modos de superação da violência que representam que a função do trabalho das mulheres vinculadas a vida doméstica retira delas a possibilidade de ressignificação das opressões vividas que, por conseguinte, exige o descolamento da figura masculina, situação apontada por Federici (2017). A personagem de T1 forma-se em direito e passa a exercer a função numa delegacia da mulher; em $\mathrm{T} 2$, a personagem vira conferencista $\mathrm{e}$ ativista no combate à violência; $\mathrm{T} 4$, passa a gerar sua própria renda com venda de bolos e afins; T5, há a realização de um sonho pessoal, uma viagem, simbólico da segurança adquirida; e, em T6, a personagem reelabora a violência sofrida e se vê fortalecida para 
recomeçar: "Consigo olhar para trás e ver que tudo isso foi um rito de passagem extremamente violento da infância para a vida adulta." Lembra-nos aqui as vivências das personagens femininas de Insubmissas Lágrimas de Mulheres, de Conceição Evaristo, em que a resignação não tem espaço em suas histórias/trajetórias.

\section{Considerações finais}

Pela análise dos textos, pudemos avaliar que houve uma apropriação significativa acerca de um discurso em prol à igualdade de gênero e de combate à violência contra a mulher. Possivelmente a condução do processo pedagógico, bem como as escolhas dos textos que integraram as oficinas tiveram impacto nas produções textuais apresentadas. A interação com os diversos gêneros (textuais) fomentaram a construção de um novo olhar sobre a igualdade de gênero. As oficinas funcionaram como, de fato, um processo que garantiu um produto final significativo.

Tal foi o engajamento que, como resultado imediato, houve a premiação nas duas categorias, texto de ensino médio e escola promotora da igualdade de gênero. Com esse último prêmio, abriu-se outra fase do projeto com atividades de extensão com a temática em três escolas públicas de Ponta Porã. As alunas, anteriormente participantes das oficinas, passaram, então, a multiplicadoras nas escolas escolhidas.

Talvez o nosso movimento de pensar as atividades e executá-las não teriam sido tão instigantes, não houvesse assuntada a possibilidade participar do concurso. A participação revestiu de significado a própria escrita na escola, deu caráter de gênero autêntico ao e status de autor aos participantes. Além do mais, ao vincular nossa prática pedagógica a um concurso governamental, pudemos legitimá-la e diminuir os percalços que, inevitavelmente, aparecem. Olhar para essa prática de um passado, não tão distante, nos conduz a uma visada mais pessimista se considerarmos a ausência de políticas públicas - como a do Concurso Construindo a Igualdade de Gênero - no contexto atual.

Não haver políticas públicas como aquela é, por si só, uma política pública. Sendo essa de opressão e silenciamento de vozes que denunciam a desigualdade de gênero e, consequentemente, fomentam a violência contra mulheres. É sintomático dessa avalanche ultraconservadora a extinção da Secretaria de Políticas para as Mulheres, em 2016. Recentemente, é visível o aumento de forças de controle e criminalização do trabalho docente, cerceamento de ações ancoradas nos Direitos Humanos, que só demonstram a ruína de políticas públicas que tematizam questões de gênero na escola e legitimam práticas cuja existência se justifica tão somente para o combate de falácias como a "ideologia de gênero".

Passados os anos dessa experiência em solo fronteiriço, sentimos a necessidade de, hoje, relatar. Fez-se urgente e necessário. Em tempos marcados por regimes totalitários e de achatamento das diferenças, ações na escola como as oficinas do projeto "Igualdade de gênero na diversidade dos gêneros" fazem sentido, uma vez que vão ao encontro do que nos sugere Biroli (2018, p. 166), para quem uma educação para a igualdade e diversidade tem duplo sentido, pois: "pode orientar a atuação de professoras/es e alunas/os, de forma a diminuir o sofrimento dos indivíduos que veem reduzido o valor de sua vida", além de que "pode aumentar as chances de que as crianças venham a ser agentes na construção de relações orientadas por critérios de justiça, ampliando o respeito e solidificando vínculos numa perspectiva democrática". 


\section{Referências}

BAGNO, M. Preconceito linguístico: o que é, como se faz. Loyola: São Paulo, 2002.

BIROLI , F. Gênero e desigualdades: limites da democracia no Brasil. São Paulo: Boitempo, 2018.

BRASIL. Lei $n .{ }^{\circ} 11.340$, de 7 de agosto de 2006.

. Lei $n^{\circ} 13.104$, de 9 de março de 2015.

Lei $n^{\circ} 13.718$, de 24 de setembro de 2018.

COPE, B.; KALANTZIS, M. Multiliteracies': New Literacies, New Learning. Pedagogies: An International Journal, 4(3):164- 195, 2009.

DOLZ, J.; NOVERRAZ, M.; SCHNEUWLY, B. Sequências didáticas para o oral e a escrita: apresentação de um procedimento. In: SCHNEUWLY, B.; DOLZ, J. e colaboradores. Gêneros orais e escritos na escola. [Tradução e organização: Roxane Rojo e Glaís Sales Cordeiro]. Campinas-SP: Mercado de Letras, 2004.

DUNKER, C. Reinvenção da intimidade: políticas do sofrimento cotidiano. São Paulo: Ubu, 2017.

FEDERICI, S. Calibã e a bruxa. Mulheres, corpo e acumulação primitiva. São Paulo: Elefante, 2017.

GALEANO, E. El libro de los abrazos. Los nadies. Madrid: Siglo XXI, 1993.

GARCÍA CANCLINI, N. Diferentes, desiguais e desconectados. Trad. Luiz Sérgio Henriques. $3^{\text {a }}$ ed. Rio de Janeiro: UFRJ, 2009.

hooks, b. O feminismo é para todo mundo: políticas arrebatadoras. 4ed. Rio de Janeiro: Rosa dos Tempos, 2019.

JUNQUEIRA, R. Pedagogia do armário: a normatividade em ação. Revista Retratos da Escola, Brasília, v. 7, n. 13, p. 481-498, jul./dez. 2013.

KILOMBA, G. Memórias de plantação. Episódios de racismo cotidiano. Rio de Janeiro: Cobogó, 2019.

MAHER, T. M. A educação do entorno para a interculturalidade e o plurilingüismo. In: KLEIMAN, A.; CAVALCANTI, M. Linguística aplicada: suas faces e interfaces. Campinas: Mercado de Letras, 2007. p. 235-270.

MINAYO, M. C.S. Laços perigosos entre machismo e violência. Revista Ciência \& Saúde Coletiva, 10(1), p. 23-26, (2005). 
MISKOLCI, R.; CAMPANA, M. 'Ideologia de Gênero': notas para a genealogia de um pânico sexual contemporâneo. Sociedade e Estado, v. 32, p. 725-747, 2017.

MOITA LOPES, L. P. Uma Linguística Aplicada Mestiça e Ideológica: Interrogando o campo como linguista aplicado. In: MOITA LOPES, L. P. Por uma Linguística Aplicada Indisciplinar. São Paulo: Parábola, 2006. p. 13-44.

PENNYCOOK, A. Uma Linguística Aplicada transgressiva. In: MOITA LOPES, L. P. Por uma Lingüística Aplicada INdisciplinar. São Paulo: Parábola Editorial, 2006. p. 6784.

PISCITELLI, Adriana. Gênero: a história de um conceito. In: ALMEIDA, H. B.; SZWAKO, J. Diferenças, Igualdade. São Paulo: Berlendis \& Vertecchia, 2009. p. 116148.

ROJO, R. H. R. Letramentos múltiplos, escola e inclusão social. São Paulo: Parábola, 2009.

ROJO, R. H. R.; BARBOSA, J. P. Hipermodernidade, multiletramentos e gêneros discursivos. São Paulo: Parábola Editorial, 2015.

SAFFIOTI, H. I. B. Violência de gênero lugar da práxis na construção da subjetividade. Lutas Sociais. São Paulo, PUC, p.59-79, 1997.

SANTOS, C. M.; IZUMINO, W. P. Violência contra as Mulheres e Violência de Gênero: Notas sobre Estudos Feministas no Brasil. Estudios Interdisciplinarios de América Latina y Caribe. v. 16, n. 1, p. 147-164, 2005.

SOARES, B. M. A Antropologia no Executivo: Limites e Perspectivas. In: CORREAA, M. Gênero \& Cidadania. São Paulo, PAGU/Núcleo de Estudos de Gênero, UNICAMP, 2002, p. 31-45.

SOARES, F. F; CHAVES, G.; FELIX, J. O que querem ensinar do nosso sexo? A influência do Congresso Nacional sobre gênero e sexualidade nas escolas. EDUCAÇÃO E EMANCIPAÇÃO (UFMA), v. 12, p. 94-117, 2019.

WAISELFISZ, J. J. Mapa da violência 2015: Homicídio de mulheres no Brasil. São Paulo: Flacso, 2015.

. Mapa da violência 2012: Atualização Homicídio de Mulheres no Brasil. São Paulo: Flacso, 2012.

Recebido em 31 de maio de 2020

Aceito em 20 de junho de 2020 